\title{
Tungsten coating by ATC Plasma Spraying on CFC for WEST tokamak
}

\author{
M. Firdaouss ${ }^{\mathrm{a},}{ }^{*}$, C. Desgranges ${ }^{\mathrm{a}}$, C. Hernandez ${ }^{\mathrm{a}}$, C. Mateus ${ }^{\mathrm{b}}$, H. Maier ${ }^{\mathrm{c}}$, B. Böswirth ${ }^{\mathrm{c}}$, H. Greuner ${ }^{\mathrm{c}}$, F. Samaille ${ }^{\mathrm{a}}$, \\ J. Bucalossi ${ }^{\mathrm{a}}$ and M. Missirlian ${ }^{\mathrm{a}}$ \\ ${ }^{a}$ IRFM, CEA Cadarache, F-13108 SAINT PAUL LEZ DURANCE, FRANCE \\ ${ }^{\mathrm{b}}$ Saint Gobain Coating Solutions, 50 rue du Mourelet, F-84093 AVIGNON, FRANCE \\ ${ }^{c}$ Max-Planck-Institut für Plasmaphysik, Boltzmannstr. 2, D-85748 GARCHING, GERMANY \\ E-mail: mehdi.firdaouss@cea.fr
}

\begin{abstract}
In the field of fusion experiments using a tokamak, the plasma facing components (PFC) are the closest object to the hot plasma. Due to the plasma-wall interaction, the material composing the PFC may enter the plasma and disturb the experiments. In the past, the main material for PFC was carbon (CFC, graphite), while the future reactors like ITER will be fully metallic, in particular tungsten.

The Tore Supra tokamak has been transformed in an x-point divertor fusion device within the frame of the WEST (W-for tungsten-Environment in Steady-state Tokamak) project in order to have plasma conditions close to those expected in ITER. The PFC other than the divertor has been coated with W to transform Tore Supra into a fully metallic environment. Different coating techniques have been selected for different kind of PFC. This paper gives an overview on the coating process used for the antennae protection limiter, the associated validation program and concludes on the adequacy of the W coating with the WEST experimental program requirements and gives perspectives on the development to be pursued.
\end{abstract}

Keywords: coatings, plasma facing components, tungsten, thermal spraying

\section{Introduction}

The development of plasma facing components (PFC) technology towards to the requirements of a fusion device goes through the use of metals as plasma facing material, and in particular tungsten (W), instead of the carbon material used in the past. The main objective of the WEST project is to manufacture and test an ITER-like actively cooled tungsten divertor, and provide a full tungsten environment [1]. Besides the ITER-like actively cooled plasma facing units (PFU) to be tested at WEST lower divertor, other WEST PFC make use of W coatings, as this is well adapted for less heavily loaded areas (lower heat and particle loads, hence erosion rate). $\mathrm{W}$ coatings also allow using existing carbon PFC to decrease the costs and the risks associated with the design and the manufacturing of new components [2].

The 10 antennae protections, located on both sides of the 5 antennae used in WEST (2 Lower Hybrid (LH) launchers and 3 Ion Cyclotron Resonant Heating (ICRH) antennae), are also reused. They are made of CFC N11 tiles that are brazed onto the water cooled support. Therefore it was not possible to dismantle the antennae protection for coating, whose length is around $1 \mathrm{~m}$ (Fig. 1).

The first part of the paper deals with the general context of the R\&D phase. The second part presents the requirements for these coatings as well as the associated quality checks/ or assessment. Then the process and the resulting coating are presented. The last part deals with the qualification of this coating trough high heat flux (HHF) tests. Finally, the paper concludes on the adequacy of this coating process with the WEST experimental program, and gives perspectives on the development to be pursued.

\section{General context}

The issue raised by $\mathrm{W}$ coating on a CFC for fusion application have been investigated for JET ITER-like Wall project more than 10 years ago [3]. Several techniques and suppliers have been compared, for thin $(<15 \mu \mathrm{m})$ and 
thick coatings $(\sim 200 \mu \mathrm{m})$. The conclusion of this work is that thin coating can be recommended for low cycling, in particular with the use of a Mo interlayer between W and CFC. Thick coating can be recommended in any place, despite some adherence problem due to the thermal mismatch between $\mathrm{W}$ and CFC. Note that an interlayer of rhenium was used by some suppliers with thick coating, to limit the formation of tungsten carbides. However, the thick coatings were developed only at the sample scale, and not retained as the main solution for JET requirements $[4,5]$.

Concerning the antennae protection of the WEST project, it was decided to have thick coating on these components. Indeed, they are not replaceable and difficult to unmount for maintenance. Therefore the coating has to be as thick as possible to overcome the sputtering issues, but also thin enough not to raise issue of stress interface in the coating and early delamination. Moreover, the surface of the CFC N11 is very irregular due to the carbon fibres. The compromise was to develop a $\mathrm{W}$ coating as thin as possible to fully cover the carbon fibre, overcoming its roughness.

One of the two suppliers that developed thick W coatings for JET ILW is Saint Gobain Coating Solutions. Their currently used process is called Atmosphere- and Temperature-Controlled Plasma Spray (ATC). It is performed in a controlled environment inside a sealed chamber, in a low pressure inert atmosphere, typically argon. The material to be deposited is sprayed by a plasma torch that is mounted on a movable robotic arm. The combination of a big size chamber and a robotic arm made this solution adequate for the large WEST antennae protections. In addition to their existing process developed at sample scale for JET ILW, it was asked to replace Re by Mo in order to decrease the thermal mismatch between the CFC substrate and the coating, as suggested in [6].

\section{Specifications and associated quality assessments}

Complementary to the coating thickness, which is discussed in the previous paragraph, several other specifications have been issued in order to deal with the WEST particularities:

- Ability to cover homogeneously the complex shape of the antennae protections.

- Low impurity content (in particular carbon and oxygen) that should be lower than $5 \%$ at to be compatible with plasma operation. This content is measured on samples by secondary ion mass spectrometry techniques (SIMS) or by Glow Discharge Mass Spectroscopy (GDMS).

- Density should be at least $90 \%$, to ensure adequate thermal and mechanical properties of the coating. It is measured by imbibition of detached samples.

- $\quad$ Adherence should be as high as possible. This is measured by tensile test.

- $\quad$ Surface should be exempt of defaults like scratch, crack, inclusion, spots... (visual inspection)
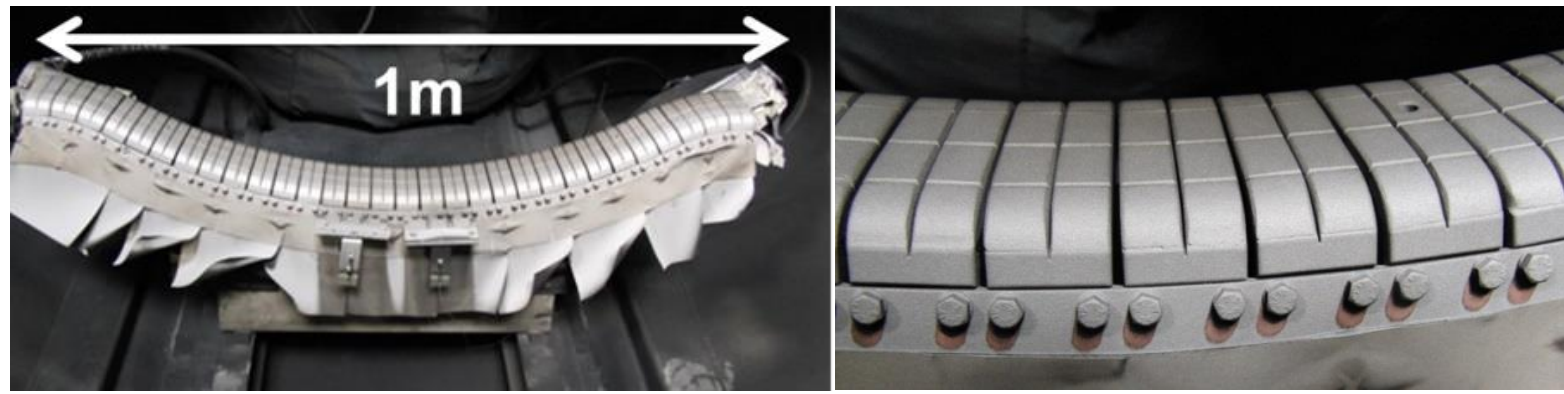

Figure 1: Antenna protection during the coating process (left) and close-up on the gaps and shaping (right)

\section{Results of the R\&D phase}

The development was divided in different phases. The first phase enabled to assess the relevant thickness on sample for both Mo and W. Several other parameters have also been optimized. Finally, these optimized parameters have been applied on a mock-up and then on the 10 antennae protections.

\subsection{Development of Mo layer}


ATC process uses the material to be coated as a powder that is injected in a plasma torch. As explained in section 2, an interlayer of Mo is coated onto the substrate. The main parameter to be optimized is the number of passes required to fully cover the CFC. With 3 passes, an $80 \mu \mathrm{m}$ thickness (Fig. 2) is obtained for given settings of the plasma torch (Ar flow rate, heating power, distance to the substrate...).

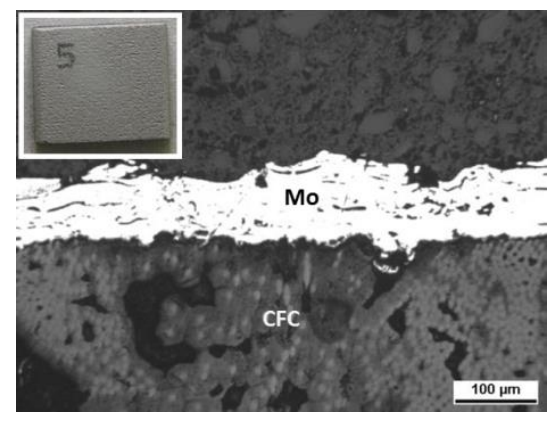

Figure 2: Cross-section view (SEM) of the Mo layer on CFC - CFC is fully covered

The resulting Mo layer is satisfying in terms of density ( $88 \%$ ) and impurity content (lower than $5 \%$ for $\mathrm{C}$ and $\mathrm{O}$ ). From these standard parameters, some optimization has been done to relieve the stress in the Mo layer and increase the adherence to the CFC. The effects of the surface burning with the plasma torch prior to the coating (vaporizing trapped carbon dusts), as well as the cooling of the surface during the coating process by Ar (moderate or strong) have been evaluated through several experiments (Table 1).

\begin{tabular}{|c|c|c|}
\cline { 2 - 3 } \multicolumn{1}{c|}{} & $\begin{array}{c}\text { Moderate } \\
\text { cooling }\end{array}$ & $\begin{array}{c}\text { Strong } \\
\text { cooling }\end{array}$ \\
\hline Burning & $6 \mathrm{MPa}$ & $4.4 \mathrm{MPa}$ \\
\hline No burning & $5 \mathrm{MPa}$ & $2.7 \mathrm{MPa}$ \\
\hline
\end{tabular}

Table 1: Failure stress for different conditions - average on 5 samples

These experiments are quantitatively compared using the failure value obtained during a tensile test (EN 582 / ASTM C633 standard modified for a $18 \times 18 \mathrm{~mm}^{2}$ section). Although quite low, the failure stress is enhanced by the burning of the surface and by a moderate cooling during coating with Ar. Failure always occurs at the interface between Mo and CFC, meaning that the Mo layer is cohesive.

\subsection{Development of $W$ layer}

The same approach is used for the development of the W layer. However, due to the differences in the material properties of Mo and $\mathrm{W}$, the injection parameters, and in particular the heating power and the distance between the torch and the surface, have to be modified to increase density. The torch power is increased by $20 \%$ from $50 \mathrm{~kW}$ to $60 \mathrm{~kW}$, while the distance to the surface decreases from $180 \mathrm{~mm}$ to $130 \mathrm{~mm}$. With this set of parameters, the thickness of the $\mathrm{W}$ is found to be at least $90 \mu \mathrm{m}$ (3 passes) for properly covering the Mo layer (Fig. 3). There is no gap between the different passes, and the porosity is strongly minimized.
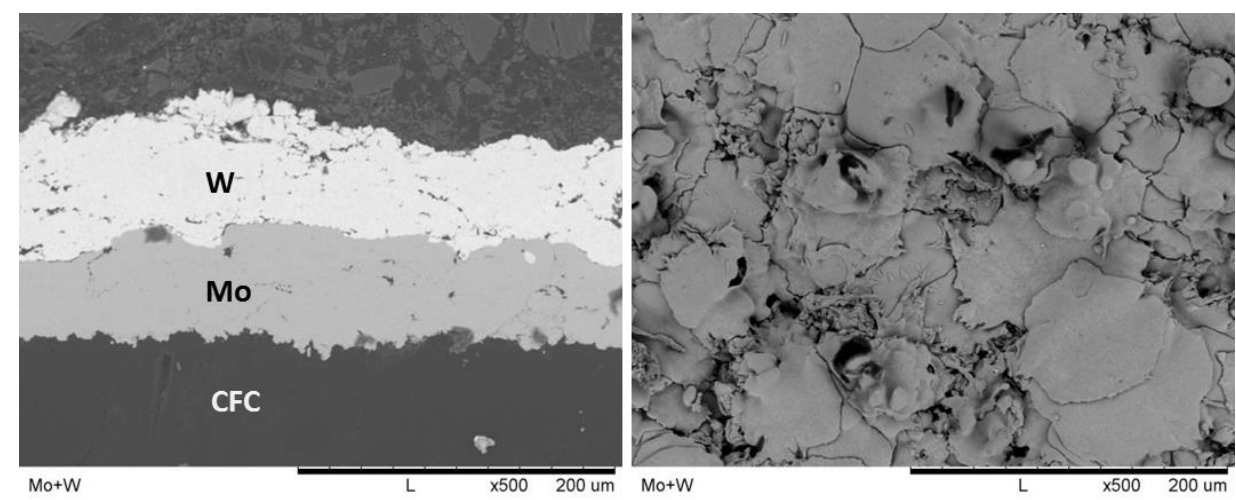
Figure 3: Cross section and surface views (SEM) of the W/Mo layers on CFC - W is not porous / W splats are regular and uniform

The resulting $\mathrm{W}$ layer is satisfying in terms of density ( $88 \%$ ) and impurity content (lower than $5 \%$ for $\mathrm{C}$ and $\mathrm{O}$ ). From these standard parameters, some optimization has been done to enhance the properties of the $\mathrm{W}$ layer. The effects of the sand blasting of the Mo surface prior to the coating, as well as the cooling of the surface during the coating process by $\mathrm{Ar}$ (moderate or strong during $\mathrm{W}$ coating, and moderate or none during Mo coating) have been evaluated trough several experiments (Table 2).

\begin{tabular}{|c|c|c|c|c|}
\cline { 2 - 5 } \multicolumn{1}{c|}{} & \multicolumn{2}{c|}{ No cooling Mo } & \multicolumn{2}{c|}{ Moderate Cooling Mo } \\
\cline { 2 - 5 } \multicolumn{1}{c|}{} & $\begin{array}{c}\text { Moderate } \\
\text { cooling W }\end{array}$ & $\begin{array}{c}\text { Strong } \\
\text { cooling W }\end{array}$ & $\begin{array}{c}\text { Moderate } \\
\text { cooling W }\end{array}$ & $\begin{array}{c}\text { Strong } \\
\text { cooling W }\end{array}$ \\
\hline Sand blasting & $2.2 \mathrm{MPa}$ & N/A & $2.6 \mathrm{MPa}$ & N/A \\
\hline No sand blasting & $2.0 \mathrm{MPa}$ & $3.0 \mathrm{MPa}$ & Delamination & $3.4 \mathrm{MPa}$ \\
\hline
\end{tabular}

Table 2: Failure stress for different conditions - average on 5 samples

These experiments are quantitatively compared using the failure value obtained during a tensile test. The failure stress does not vary significantly with the sand blasting. This additional step is therefore not considered as an essential step for the process. A strong cooling of the $\mathrm{W}$ coating increases the adherence of the coating to its substrate. Failure always occurs at the interface between Mo and CFC, meaning that both $\mathrm{W}$ and Mo layers are cohesive.

\subsection{Coating of an antennae protection mock-up}

The step after the development on samples described previously is the processing of a mock-up that represents $10 \%$ of a complete antennae protection (Fig. 4). The main objective of this step is to take into account the real geometry of the protection, including particular shape, gaps with variable size and the cooling system. The cooling system is used during the coating process, in order to decrease the temperature of the substrate and possibly to increase the adherence of the coating.

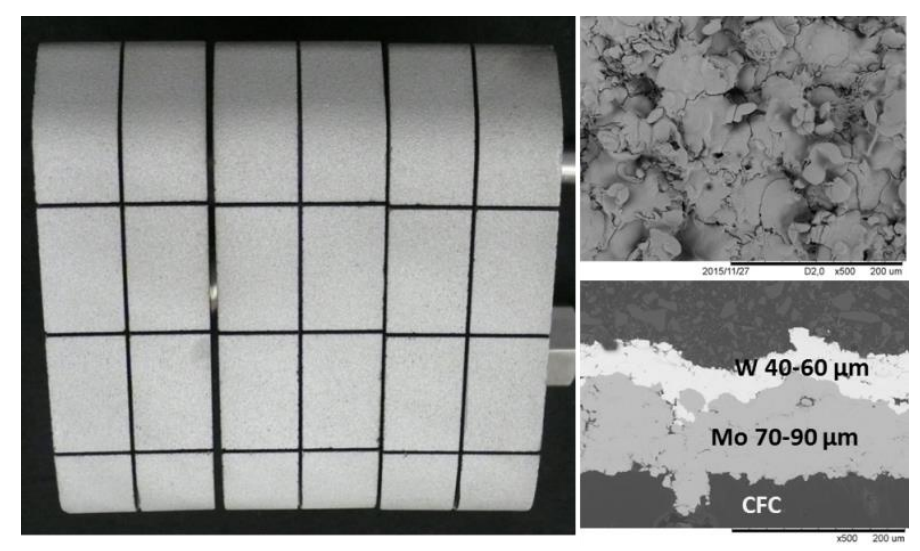

Figure 4: Antennae protection mock-up, cross section and surface views (SEM) - W/Mo layers are similar to those found during $R \& D$ phase

The properties of the multi-layer coating are checked on samples that are coated in the same batch. The sample exhibits similar properties to those found at the end of the R\&D step. Only the thickness of the W coating is slightly lower than expected. One pass during the $\mathrm{W}$ coating is added for the series production.

\subsection{Additional development}

The $R \& D$ has been extended outside of the main objectives described previously. The first extension was to evaluate the possibility of adding Boron on top of the $\mathrm{W}$ layer, in the case of incompatibility of the $\mathrm{W}$ from the 
antennae protections with the plasma operation. This B coating has been developed following the same optimization phases than the Mo and $\mathrm{W}$ coatings. Results at the sample scale are satisfying in terms of density, purity and adherence. This coating still would have to be qualified by HHF tests.

The second extension was to develop a process of coating on Copper, in order to cover with $\mathrm{W}$ the Faraday screens of the ICRH antennae. Results at sample scale were also satisfying in terms of density, purity and adherence. The process has been applied on a half size Faraday screen mock-up. This mock up is being qualified by HHF tests at the High Heat Flux Test Facility (HHFTF) from the Institute for Plasma Research (India), for several hundreds of cycles and up to a few $\mathrm{MW} / \mathrm{m}^{2}$.

\section{Experimental HHF evaluation}

\subsection{Definition of the conditions}

During the past operations of Tore Supra, the antenna protection limiter had a maximal operation temperature of $1000^{\circ} \mathrm{C}$, corresponding to $10 \mathrm{MW} / \mathrm{m}^{2}$ locally. This temperature will be the limit during the plasma operation in WEST. Therefore this limit has been chosen as the maximal temperature for HHF test.

HHF tests in the facility GLADIS [7] have been carried out on the mock-up of the antennae protection to validate the $\mathrm{W}$ coating process. The tests consist to apply repeatedly heat loads on the same area at a given level, in order to evaluate the fatigue of the coating. Finite element modelling has been done using ANSYS, to determine the appropriate peak heat flux to reach the $1000^{\circ} \mathrm{C}$ limit. The Gaussian heat flux profile of the GLADIS beam with a central heat flux of $8 \mathrm{MW} / \mathrm{m}^{2}$ resulted in a surface temperature of about $1000^{\circ} \mathrm{C}$ after $15 \mathrm{~s}$ loading close to steady-state (Fig. 5).

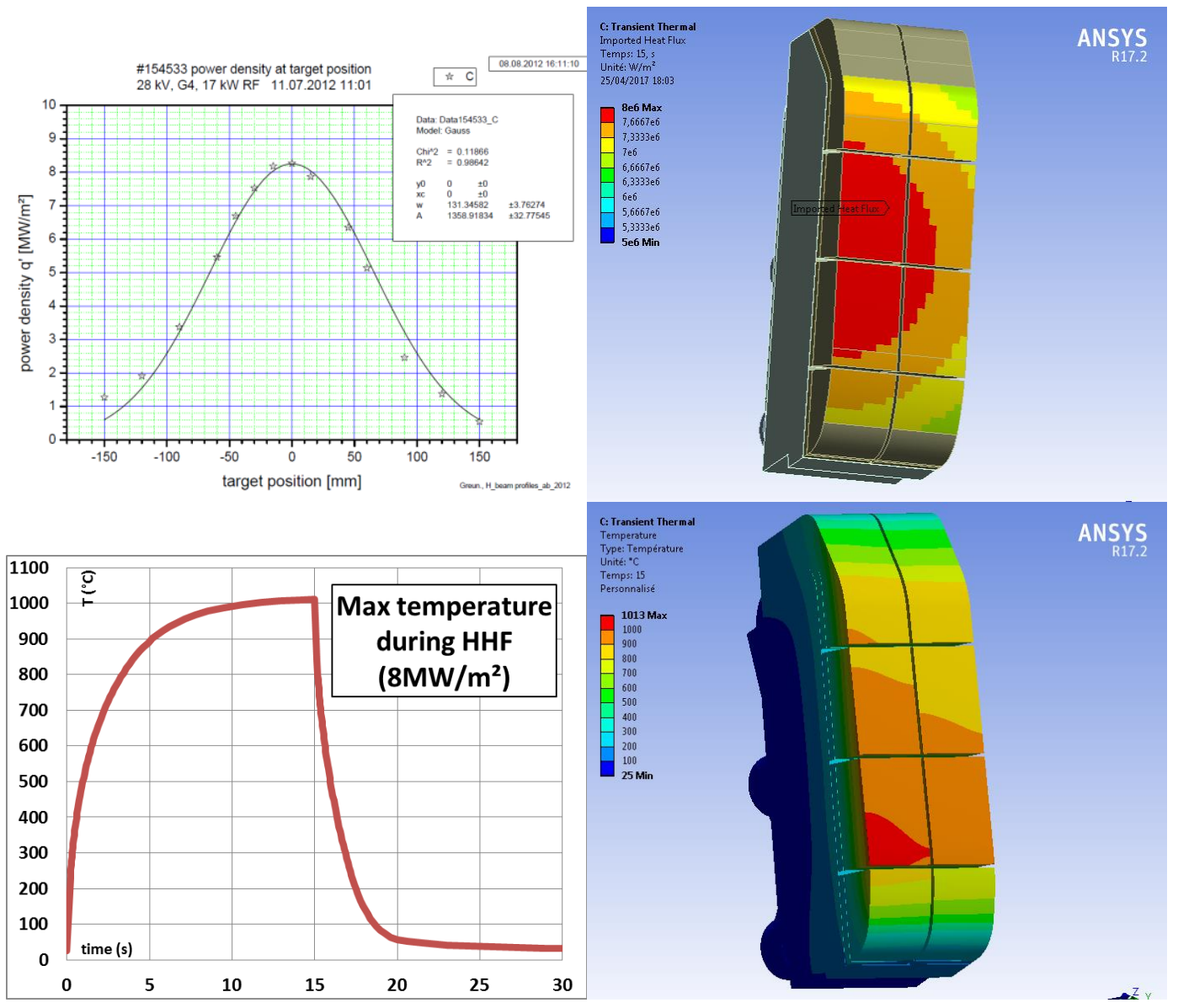

Figure 5: Preparation of the HHF tests: Gaussian profile of GLADIS neutral beam, heat flux profile on the mock-up (Ansys), maximal temperature with time and temperature distribution at $15 \mathrm{~s}-1000^{\circ} \mathrm{C}$ is attained after 
The HHF test procedure consists of 500 cycles at $8 \mathrm{MW} / \mathrm{m}^{2}$ during 15 seconds and then 45 seconds cooling, while an initial screening at $3 \mathrm{MW} / \mathrm{m}^{2}$ is performed in order to define the initial response of the coating on the mock-up. This screening is repeated after half of the cycles and at the end, to compare with the initial response.

\subsection{Results of the HHF cycling test}

Since the initial screening at $3 \mathrm{MW} / \mathrm{m}^{2}$ before cycling, the mock-up has shown the two upper defects of the vertical edges shown on Fig. 6. Note that both defects did not appear on the most heated areas. Three other defects appeared during the cycling at $8 \mathrm{MW} / \mathrm{m}^{2}$.

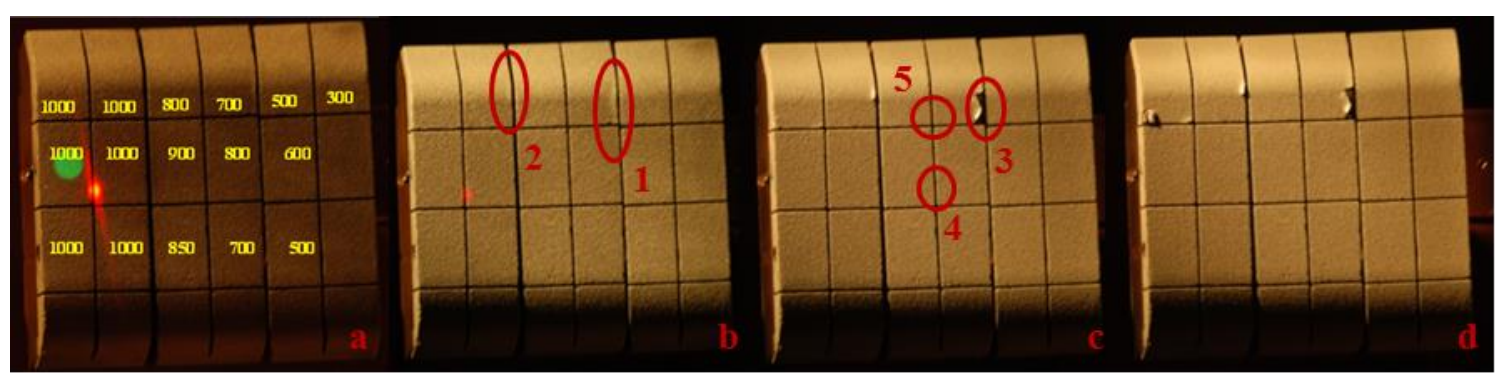

Figure 6: Pictures of the mock-up - (a) initial surface, (b) after initial screening, (c) after 280 cycles and (d) after 500 cycles. The position of the beam center is marked with the red laser dot, green spot corresponding to the pyrometer view - Five defects are evolving

Table 3 recapitulates the localization of all the 5 defects, at which pulse number they appeared, and the pulse number at which the evolution stopped. This evolution is estimated using an infrared camera, assessing that the evolution has stopped when the infrared picture does not evolve from pulse to pulse.

\begin{tabular}{cccc}
\hline Defect & Appearance & Evolution & Localisation \\
\hline $\mathbf{1}$ & 1 & 200 & Edge \\
$\mathbf{2}$ & 1 & 280 & Edge \\
$\mathbf{3}$ & 11 & 280 & Corner \\
$\mathbf{4}$ & 17 & 200 & Corner \\
$\mathbf{5}$ & 91 & 350 & Corner \\
\hline
\end{tabular}

Table 3: Defects appearance and evolution

It is clear from table 3 that all the defects appeared quickly (before 100 cycles). Therefore the failures did not appear from fatigue issue, but are more due to a latent weakness caused by stress singularity at the edges and corners. This is also confirmed by the observation that all the defects appeared and evolved on an edge or a corner, and not in the centre of the tile. Moreover, the temperature and the number of cycles are too low to allow for the phenomenon of $\mathrm{W}$ carbidization with the formation of $\mathrm{W}_{2} \mathrm{C}$ and $\mathrm{WC}$, brittle compounds that are likely to break under thermal loads $[8,9,10]$.

\subsection{Post-mortem analysis}

To confirm the hypothesis made previously, post mortem analysis have been carried out using a SEM. Cuts have been made at 9 different locations (see Fig. 7), to analyse the potential impact of the temperature on the microstructure (yellow dotted lines) and also to look precisely at the delaminated areas (red dotted lines). 


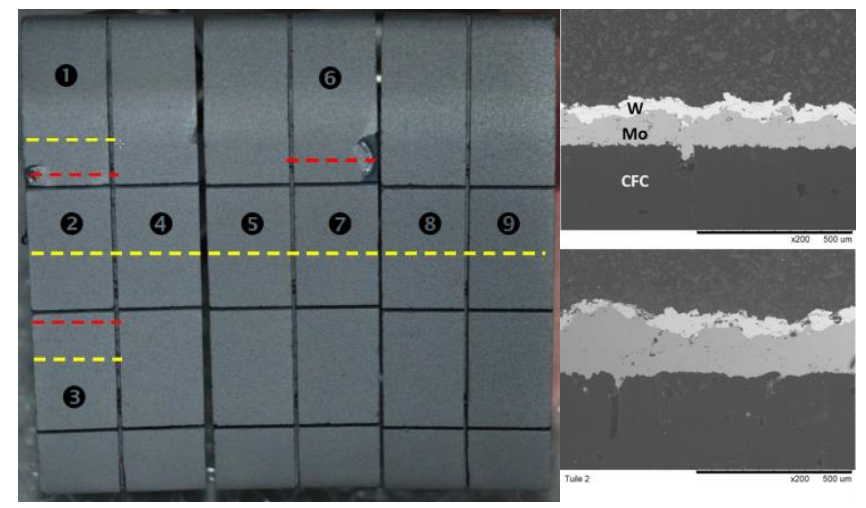

Figure 7: Cross sections done for SEM observations and results on reference sample (top) and location 2 (bottom) - no carbon migration through Mo and W

As shown in Fig. 7, there is no difference in the microstructure between the reference sample and the location 2 that corresponds to the most heated area. Similar observations are done for all the yellow cuts. This confirms that the maximal temperature of $1000^{\circ} \mathrm{C}$ is not high enough to allow the migration of $\mathrm{C}$ trough $\mathrm{Mo}$ and $\mathrm{W}$ and the formation of tungsten and molybdenum carbides, as shown in [10].

SEM observation on red dotted lines on the three locations are similar, therefore only the most noticeable delamination is shown on Fig. 8 below, corresponding to the location 6 .
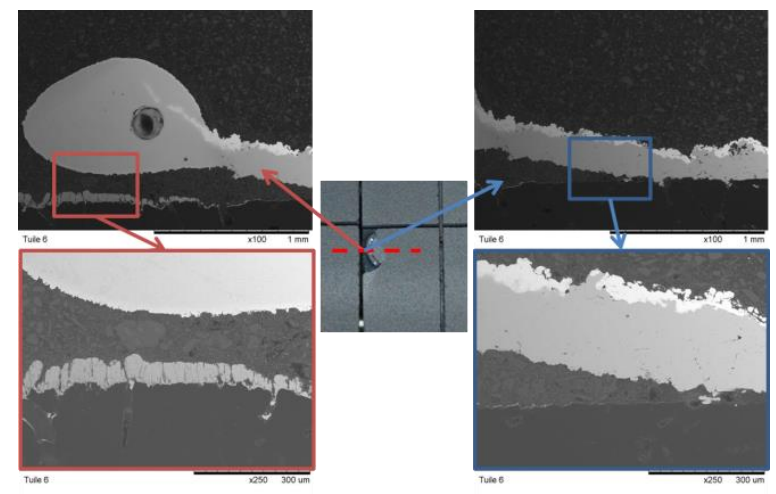

Figure 8: SEM views on the delamination at the location 6 - Failure occurred at the CFC/Mo interface and W disappeared

Delamination started from the corner, and the Mo/W coating has been winding around itself while the failure was increasing. It occurred at the location found to be the weakest during the optimisation of the multi-layer coating, the interface between Mo and CFC. CFC is almost totally exposed, except on the location within the red frame on Fig. 8, where a $40 \mu \mathrm{m}$ of Mo still exists. W has almost disappeared from the delaminated area

It was concluded from these observations that the weakness of the coating was coming from the geometry of the tiles, with straight edges. Consequently all the edges of the antenna protections have been rounded by hand before coating, to avoid as much as possible the corners and edges delamination during operations.

\section{Conclusion and perspectives}

A W coating process by Atmosphere and Temperature Controlled Plasma Spray on CFC substrate using Mo as a compliance material is shown in this paper, as well as the qualification program. Several challenging issues have been solved during the R\&D, in particular handling complex shapes on large scale components and optimizing the adherence.

In particular, it is successfully qualified under high heat flux tests to sustain the expected temperatures (up to $1000^{\circ} \mathrm{C}$ ) during WEST experiments, with the assumption that the rounded edges will prevent the premature delamination of the corners. It also copes with the operational requirements like thickness, $90 \%$ density and low impurity content required for plasma operations. 
The 10 antennae protections limiters have been coated with the process described in this paper. 4 of them are currently mounted inside WEST with the LH antennae, and the 6 others should be mounted with the ICRH antennae before the end of 2017.

The performance of the $\mathrm{W}$ coatings in a tokamak environment; with combined effects (sputtering, steady state load, transient loads, disruptions...) will be assessed during WEST operation. Additional R\&D activities on reparation process, including ablation of the coating, are already on-going in order to be able to heal $\mathrm{W}$ coatings damaged during plasma operation.

\section{Acknowledgements}

This work has been carried out within the framework of the EUROfusion Consortium and has received funding from the Euratom research and training programme 2014-2018 under grant agreement No 633053. The views and opinions expressed herein do not necessarily reflect those of the European Commission.

\section{References}

1. J. Bucalossi et al., Fusion Engineering and Design 89 (2013) 907-912.

2. M. Firdaouss et al., Fusion Engineering and Design, https://doi.org/10.1016/j.fusengdes.2017.02.087.

3. R. Neu et al., 10.1088/0031-8949/2007/T128/029, 2007 Phys. Scr. T128 (2007) 150

4. Maier $\mathrm{H}$ et al, 2009 Phys. Scr. T 138014031

5. G.F. Matthews et al., Journal of Nuclear Materials 390-391 (2009) 934-937

6. C. Ruset, et al., Phys. Scripta T128 (2007) 171-174.

7. H. Greuner et al., Journal of Nuclear Materials 367-370 (2007) 1444

8. H. Maier et al., 10.1088/0031-8949/T167/1/014048, 2016 Phys. Scr. T167 (2016) 014048

9. M. Rasinski et al., Thin Solid Films 531 (2013) 21-24

10.C. Ruset et al Fus. Eng \& Des. 88 (2013)1690-1693 